\title{
The normative power of food promotions: Australian children's attachments to unhealthy food brands
}

\author{
Bridget Kelly,* , Becky Freeman ${ }^{2}$, Lesley King ${ }^{2}$, Kathy Chapman ${ }^{3}$, Louise A Baur ${ }^{2,4}$ \\ and Tim Gill ${ }^{2}$ \\ ${ }^{1}$ Early Start Research Institute, School of Health \& Society, University of Wollongong, Northfields Avenue, \\ Wollongong, NSW 2522, Australia: ${ }^{2}$ Prevention Research Collaboration, Sydney School of Public Health, University \\ of Sydney, Sydney, NSW, Australia: ${ }^{3}$ Cancer Council NSW, Woolloomooloo, NSW, Australia: ${ }^{4}$ The Children's \\ Hospital at Westmead Clinical School, Sydney Medical School, University of Sydney, Sydney, NSW, Australia
}

Submitted 11 October 2015: Final revision received 27 April 2016: Accepted 9 May 2016: First published online 13 June 2016

\begin{abstract}
Objective: The formation of food brand associations and attachment is fundamental to brand preferences, which influence purchases and consumption. Food promotions operate through a cascade of links, from brand recognition, to affect, and on to consumption. Frequent exposures to product promotions may establish social norms for products, reinforcing brand affect. These pathways signify potential mechanisms for how children's exposure to unhealthy food promotions can contribute to poor diets. The present study explored children's brand associations and attachments for major food brands.

Design: A cross-sectional online survey was conducted. Fourteen study brands were used, with each child viewing a set of seven logos. The questionnaire assessed perceptions of food brands and perceptions of users of brands, using semantic differential scales, and perceived brand 'personalities', using Likert scales.

Setting: New South Wales, Australia, October-November 2014.

Subjects: Children aged 10-16 years ( $n$ 417).

Results: Children demonstrated strong positive affect to certain brands, perceiving some unhealthy food brands to have positive attributes, desirable user traits and alignment to their own personality. Brand personality traits of 'smart' and 'sporty' were viewed as indicators of healthiness. Brands with these traits were ranked lower for popularity.

Conclusions: Children's brand associations and attachments indicate the potential normative social influences of promotions. While children are aware of brand healthiness as an attribute, this competes with other brand associations, highlighting the challenge of health/nutrition messaging to counter unhealthy food marketing. Restricting children's exposure to unhealthy food marketing and the persuasive nature of marketing is an important part of efforts to improve children's diet-related health.
\end{abstract}

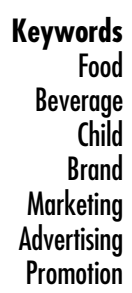

Children's exposure to unhealthy food and beverage promotions is increasingly recognised by public health professionals $^{(1)}$ and leading global health organisations ${ }^{(2)}$ as a probable contributor to poor diets, weight gain and, consequently, non-communicable diet-related diseases. Globally, monitoring data have identified that children are exposed to high levels of food promotions across all media platforms and a range of settings, and that promoted products are predominantly high in added fat, sugar and/or sodium (referred to as 'unhealthy') ${ }^{(3)}$. These data have also identified that food and advertising industry codes of practice for responsible marketing to children have been largely ineffective in reducing children's exposures to such promotions ${ }^{(4)}$. Yet, few governments have introduced regulations to limit children's exposure to promotions for unhealthy foods, citing a lack of evidence linking marketing exposure to diet and weight outcomes $^{(5,6)}$.

Marketing is known to operate through a cascade pathway from brand recognition, to affect, and on to behaviour $^{(7)}$, and there is considerable evidence to support this sequenced set of effects ${ }^{(8)}$. The development of 'brand equity' is a major driver that propels people along this pathway that leads ultimately to the consumption of 
products. Brand equity represents the value that is added to a product as a consequence of being linked to the brand (a name or a symbol) ${ }^{(9)}$ and comes about as a result of brand knowledge, perceptions and attachments ${ }^{(10)}$. Brand awareness must, clearly, precede brand perceptions and attachments, and this awareness is linked to brand exposures $^{(10)}$. The frequency of exposure, as well as the persuasive power of promotions (content and creative strategies), creates the potential for brand equity (positive perceptions and strong attachments) ${ }^{(2)}$. From a public policy perspective, limiting children's exposure to brand messages for unhealthy foods and beverages, and the persuasive power of these promotions, could stifle the cascade of effects of marketing by suppressing brand awareness, perceptions and attachment and thus limiting brand equity.

Children's views about major food brands provide an indicator of relative brand equity and can be used as a predictor of intention to consume such products. Research with adults ${ }^{(11)}$ and children ${ }^{(12)}$ has shown that strong, positive brand perceptions predict brand choice and purchase behaviours. Brand perceptions can include beliefs about brand attributes and benefits, and perceptions about users of the brand. Brand attachment, or the extent that a person self-identifies with a brand, is an even stronger predictor of actual consumption behaviour ${ }^{(11)}$. Brand attachment involves a cognitive and emotional connection between a person and the brand, and is shown through thoughts and feelings about the brand's relationship to self ${ }^{(11)}$. Marketing campaigns largely seek to build positive images of, and relationships with, brands. Consequently, research that uses brand-as-a-person metaphors to assess perceptions of brand personalities can provide insights regarding brand perceptions and attachment and potential purchase and consumption behaviours $^{(13)}$. Brand perceptions may be particularly important for older children in their formation of brand preferences. Piaget's theory of cognitive development posits that older children consider multiple attributes when forming preferences, while younger children may consider simple attributes, such as the visual aspects of a brand, in making choices ${ }^{(14)}$. However, as age increases from about 11 years, children's scepticism towards advertising also increases ${ }^{(15)}$.

The present study aimed to explore Australian children's brand perceptions and attachments (together, described as 'brand affect') for major food and beverage brands. As such, it contributes evidence of brand equity, and thus can form an indicator of the extent and impact of prior brand exposures and may predict food purchase and consumption behaviours. Brand affect, which represents a person's favourable or unfavourable evaluation of a brand $^{(16)}$, was compared with reported levels of commercial television viewing (as a proxy for television advertising exposure) and social media engagement with food brands to identify affect-exposure relationships. We hypothesised that children who were exposed to a greater amount of television adverting and who had engaged with food brands on social media would have more positive affect towards food brands. We also predicted that younger children would be less sceptical of marketing and branding and would rate brands more favourably. We expected that unhealthy brands would be seen to be more favourable and that users of these brands were perceived as more popular due to the ubiquity of commercial messages about these types of brands.

\section{Methods}

\section{Sampling}

A cross-sectional online survey was conducted with 10-16-year-old children living in New South Wales, Australia, during October-November 2014. The target sample was 400 children, which allowed for response comparisons across demographic groups. This sample was deemed to provide sufficient cell sizes for calculating differences between age (two groups), sex (two groups) and socio-economic status (SES; three groups) for their responses to question scales (commonly five categories). Approximately 7600 parents who were panel members of a consumer research panel (from McNair Ingenuity) were contacted by email, asked to complete a short screener survey to assess eligibility and then asked to invite their child to participate in the survey. A total of 582 parents successfully completed the screener process (see online supplementary material, Supplemental Figure 1). Sample quotas were established for child age (approximately equal numbers for all year groups), sex (approximately equal numbers of boys and girls) and based on postcode of residence using the Australian Bureau of Statistics Socio-Economic Indexes for Areas (spread of low, medium and high SES) ${ }^{(17)}$. Where there was more than one eligible child in a household, preference was given to the oldest child as it was anticipated that older adolescents would be more difficult to recruit. Panel members had previously agreed to be contacted by this company for survey purposes. The emailed link to the online survey contained a unique identifier to monitor participation and facilitate follow-up by email, as required. Up to two reminder emails were sent. Participants were given a $\$$ AU 10 gift voucher for participating. The study was approved by the University of Sydney Human Research Ethics Committee.

\section{Measures}

A purpose-designed questionnaire was developed including measures of: (i) sociodemographic characteristics (sex, age, residential postcode); (ii) perceptions of food brands on 5-point semantic differential scales of 'very cool' to 'very uncool', 'very exciting' to 'very unexciting', and 'very fun' to 'very boring'; (iii) perceptions of users of food brands, using 5-point semantic differential scales of 
'very sophisticated' to 'very unsophisticated', 'very popular' to 'very unpopular', and 'very sporty' to 'very unfit'; and (iv) perceptions of food brand 'personalities', using 5-point Likert sales to respond to eight statements about the brand (refer to Table 2). For this latter measure of brand personalities, children were asked to imagine that each brand was a person, such as a new student at their school. This measure was based on an earlier study from Canada, which assessed adolescents' attitudes towards a cigarette brand's personality and their identification with the brand before and after Formula 1 (motor sport) sponsorship $^{(18)}$. The current questionnaire applied this concept of self-identification with brands and made this more relevant to younger children by personifying brands as a person at their school. Media use, including their engagement with food brands on social media (particularly Facebook; i.e. if they had ever 'liked' food and drink brands) was also asked (yes/no). Volume of commercial and non-commercial television watched was also reported in $15 \mathrm{~min}$ increments for weekdays and weekend days and added to give total volume of television viewing per week. Food brand perception questions were designed by the authors, based on earlier surveys with children on their perceptions of food brands ${ }^{(19,20)}$ and self-attachment to tobacco brands ${ }^{(18)}$. Face validity of the questionnaire was achieved through the review of the tool by all members of the research team and by the market research company analysists, who are experienced in designing and undertaking social and market research. The questionnaire was first pilot-tested with eight children aged 10-16 years. Piloting revealed that the duration of the questionnaire was too long. The final questionnaire was revised to minimise repetition, clarify wording and delete questions that were perceived to be less important.

\section{Procedure}

To reduce respondent burden, the fourteen study brands (see Table 1) were split into two groups and each child was randomly allocated to view one of these groups, with each child viewing seven brands. Brands were selected to include a range of more popular and less popular, 'healthier' and unhealthy, and child-oriented and not child-oriented brands. Children were shown food/drink brand logos on-screen and asked to indicate their attitudes to brands, brand users and brand personalities.

\section{Analyses}

Data were entered in the statistical software package IBM SPSS Statistics for Windows, Version 19.0. Mean ratings of perceptions of food brands were compared for unhealthy brands and 'healthier' brands using paired $t$ tests. The proportions of children with favourable perceptions of food brands (cool, exciting, fun) by child age group (10-12 years $v$. 13-16 years) and volume of commercial television viewing (higher $v$. lower viewers based on median split) were compared using $\chi^{2}$ tests. Adjustment of $P$ values was performed using the Bonferroni method. Mean ratings of perceptions of users of food brands were compared for unhealthy brands and 'healthier' brands and by age group and television viewing group (higher $v$. lower). The proportions of children agreeing with statements about food brand 'personalities' were compared descriptively across brands. Agreement with the statement 'I would try to make friends with them' was

Table 1 Rating of brands on 'cool', 'exciting' and 'fun' scales, and mean overall brand rating, in an online survey by children aged 10-16 years ( $n$ 417), New South Wales, Australia, October-November 2014

\begin{tabular}{|c|c|c|c|c|c|c|c|c|c|}
\hline \multirow[b]{2}{*}{ Brand $\neq$} & \multirow[b]{2}{*}{ Food type } & \multicolumn{2}{|c|}{$\begin{array}{l}\text { 'Very cool' or } \\
\text { 'A little cool' }\end{array}$} & \multicolumn{2}{|c|}{$\begin{array}{l}\text { 'Very exciting' or } \\
\text { 'A little exciting' }\end{array}$} & \multicolumn{2}{|c|}{$\begin{array}{l}\text { 'Very fun' or } \\
\text { 'A little fun' }\end{array}$} & \multicolumn{2}{|c|}{$\begin{array}{c}\text { Overall } \\
\text { brand rating§ }\end{array}$} \\
\hline & & $n$ & $\%$ & $n$ & $\%$ & $n$ & $\%$ & Mean & SD \\
\hline Cadbury ( $n$ 208) & Chocolate & $190^{*}$ & 91 & 180 & 87 & 183 & 88 & 1.5 & 0.68 \\
\hline Pringles ( $n$ 208) & Crisps & 155 & 75 & 169 & 81 & 146 & 70 & $2 \cdot 1$ & 1.11 \\
\hline Freddo Frog (n 208) & Chocolate & 153 & 74 & 134 & 64 & 159 & 76 & $2 \cdot 0$ & 0.94 \\
\hline Red Rock Deli ( $n$ 208) & Crisps & 146 & 70 & 129 & 62 & 112 & 54 & $2 \cdot 3$ & 0.97 \\
\hline Coca-Cola $(n$ 209) & Sugary drink & $145 \dagger$ & 69 & 131 & 63 & 144 & 69 & $2 \cdot 2$ & 1.17 \\
\hline Mars $(n$ 208) & Chocolate & 142 & 68 & 125 & 60 & 128 & 62 & $2 \cdot 2$ & 0.96 \\
\hline McDonald's ( $n$ 208) & Fast food & $124^{\star \star \star}$ & 60 & $127^{\star \star}$ & 61 & $133^{\star \star \star}$ & 64 & $2 \cdot 3$ & $1 \cdot 19$ \\
\hline Domino's Pizza (n 209) & Fast food & 122 & 58 & 117 & 56 & 116 & 56 & $2 \cdot 4$ & 1.08 \\
\hline KFC ( $n$ 209) & Fast food & $114^{*}$ & 55 & 107 & 51 & 115 & 55 & $2 \cdot 6$ & 1.25 \\
\hline Mount Franklin (n 209)\| & Water & 111 & 53 & 69 & 33 & 59 & 28 & $3 \cdot 0$ & 1.06 \\
\hline Goulburn Valley (n 209)\| & Juice & 69 & 33 & $53^{\star}$ & 25 & 43 & 21 & $3 \cdot 3$ & 1.03 \\
\hline Red Bull ( $n$ 209) & Sugary drink & 61 & 29 & 59 & 28 & 65 & 31 & 3.5 & 1.39 \\
\hline Sumo Salad (n 209)\| & Salad bar & $55^{\star \star}$ & 26 & 52 & 25 & 52 & 25 & 3.4 & $1 \cdot 19$ \\
\hline Red Rooster ( $n$ 208) & Fast food & $50^{*}$ & 24 & $61^{*}$ & 29 & 56 & 27 & $3 \cdot 3$ & $1 \cdot 10$ \\
\hline Unhealthy brands & & & & & & & & 2.4 & 0.66 \\
\hline Relatively healthy brands & & & & & & & & $3 \cdot 2$ & 0.99 \\
\hline
\end{tabular}

Significant difference in ratings by age group (10-12 years $v .13-16$ years): ${ }^{\star} P<0.05,{ }^{\star \star} P<0.01,{ }^{\star \star \star} P<0.001$; and by volume of commercial television viewing per week (higher $v$. lower viewers based on median split): $\dagger P<0.05$.

$\ddagger$ Numbers in parentheses are the number of children who viewed each brand.

$\S$ Mean overall brand rating calculated as sum of cool, exciting, fun scales $(1=$ very positive, $5=$ very negative), dived by three to give a value out of 5 .

IIBrands that represent relatively healthier products. 
summed across all seven brands viewed by each child, with a score of 1 point for each brand with 'agree' or 'strongly agree'. Similar summed scores for each child were derived for the statements 'Other children would try to make friends with them' and 'This person would have a similar personality to me'. Summed scores were compared to reported engagement with food brands on Facebook (yes/no) and volume of commercial television watched (higher $v$. lower) using independent-samples $t$ tests. Findings were considered significant at the $\alpha=0.05$ level.

\section{Results}

\section{Sample characteristics}

Overall, 417 children completed the survey (53\% girls), with a mean age of 13 (SD 1.9) years. A spread of socioeconomic backgrounds was achieved (28\% low SES, $44 \%$ medium SES, $28 \%$ high SES). An equal number of children ( $n$ 208-209) were allocated to view each brand grouping, with similar child age and sex distributions within these groupings.

\section{Food and drink brand affect}

Perceptions of food brands

Of the eleven brands that were classified as representing unhealthy products (fast food, chocolate, crisps, sugary drinks), the mean rating across all three semantic differential scales of cool-uncool, fun-boring and excitingunexciting was $2 \cdot 4$, while for 'healthier' brands (salad bar, water, juice) the mean rating was $3.2\left(t_{376}=-14 \cdot 20\right.$, $P<0 \cdot 001)$, with 1 indicating very positive perceptions and 5 indicating very negative perceptions (Table 1 ). This indicates that children perceived unhealthy brands to be 'a little positive' (cool, exciting, fun) but healthy brands 'inbetween' positive and negative scales. Cadbury was rated as most favourable on each of the semantic differential scales (Table 1). Mean overall rating of brands was calculated as the sum of ratings on cool, exciting and fun scales, divided by three. The mean rating for Cadbury was $1 \cdot 5$, indicating that average ratings were between 'very' and 'a little' positive (cool, exciting, fun). Alternatively, brands with an average rating of more than 3.0 were negatively perceived, including Goulburn Valley juice, Red Bull, Sumo Salad and Red Rooster. Compared with older children (13-16 years), a greater proportion of younger children (10-12 years) rated McDonald's as 'very' or 'a little' cool ( $\left.51 \% v .24 \%, \chi_{1}^{2}=15 \cdot 22, P=0.001\right)$, 'very' or 'a little' exciting (74\%v. $\left.53 \%, \chi_{1}^{2}=9 \cdot 00, P=0.003\right)$ and 'very' or 'a little' fun (77\% v. $\left.55 \%, \chi_{1}^{2}=10 \cdot 38, P=0.001\right)$. Greater numbers of younger children also perceived Cadbury, KFC and Red Rooster to be 'cool', and Red Rooster to also be 'exciting'. A greater proportion of older children rated Sumo Salad as cool (33\%v. 16\%, $\chi_{1}^{2}=7 \cdot 62$, $P=0.006)$. Based on median split, those who watched more commercial television per week were significantly more likely to perceive Coca-Cola as 'very' or 'a little' cool (75\% v. 61\%, $\chi_{1}^{2}=5 \cdot 00, P=0 \cdot 03$ ). Perceptions of other brands were not associated with television viewing volume.

\section{Perceptions of users of food brands}

Relating to children's perceptions of users of brands, the eleven unhealthy brands were rated as less sophisticated (mean 2.9 (SD 0.83) on the semantic differential scale of sophisticated-unsophisticated) compared with the three 'healthier' brands (2.4 (SD 1.05)) and less sporty (3.6 (SD $0.80) v .1 .9$ ( $\mathrm{SD} 0.65$ ) on the semantic differential scale of sporty-unfit), with a rating of 1 indicating strong positive perceptions and 5 indicating strong negative perceptions. However, the unhealthy brands were rated as more popular than the three 'healthier' brands (1.7 (SD 0.78) v. 2.8 (SD 0.97 ) on the semantic differential scale of popularunpopular). Figure 1(a)-(c) shows mean ratings of brand users, separated into beverages, fast food and snacks. The mean rating on scales of 'sophisticated', 'popular' and 'sporty' for users of Coca-Cola were $1 \cdot 3,2.5$ and $3 \cdot 2$, respectively. That is, the average ratings were 'very popular'; mid-way between 'a little sophisticated' and 'in-between sophisticated and unsophisticated'; and 'inbetween sporty and unfit'. For fast food, there was an inverse relationship between ratings of 'sporty' and 'popular'. That is, users of Sumo Salad were rated as 'sporty' and also as 'unpopular'. All snacks followed a similar pattern in responses: they were rated as 'popular', 'a little sophisticated' and 'in-between sporty and unfit'. There was no difference in mean ratings by volume of commercial television watched per week (by median split). Younger children were significantly more likely to rate users of products as more sophisticated than older children, including for McDonald's (mean $3.0 v .3 .5$ ), KFC $(3 \cdot 1 v \cdot 3 \cdot 6)$, Domino's Pizza (3.0 v. 3.3) and Cadbury (2.0 v. $2 \cdot 3)$. Users of McDonald's, Mars and Cadbury were also rated as more popular by younger children, while users of KFC were perceived to be more 'sporty' (all $P<0 \cdot 05$ ). Older children perceived Red Rock Deli crisps to be more sophisticated than younger children (mean $1.2 v .2 \cdot 4$ ).

\section{Perceptions of food brand 'personalities'}

Children were then asked to imagine that each brand was a person, such as a new student at their school, and to indicate their agreement with statements on a Likert scale. If Coca-Cola was a person, the greatest proportion of children agreed they would be popular (74\%) and outgoing (68\%), compared with other brands (Table 2). Most children agreed that other children would try to make friends with Cadbury (77\%) and Coca-Cola (72\%), although only $53 \%$ of children agreed that they would try to make friends with Coca-Cola. Overall, children's perceptions of Cadbury as a person were most positive; for this brand, the greatest proportion of children agreed that 

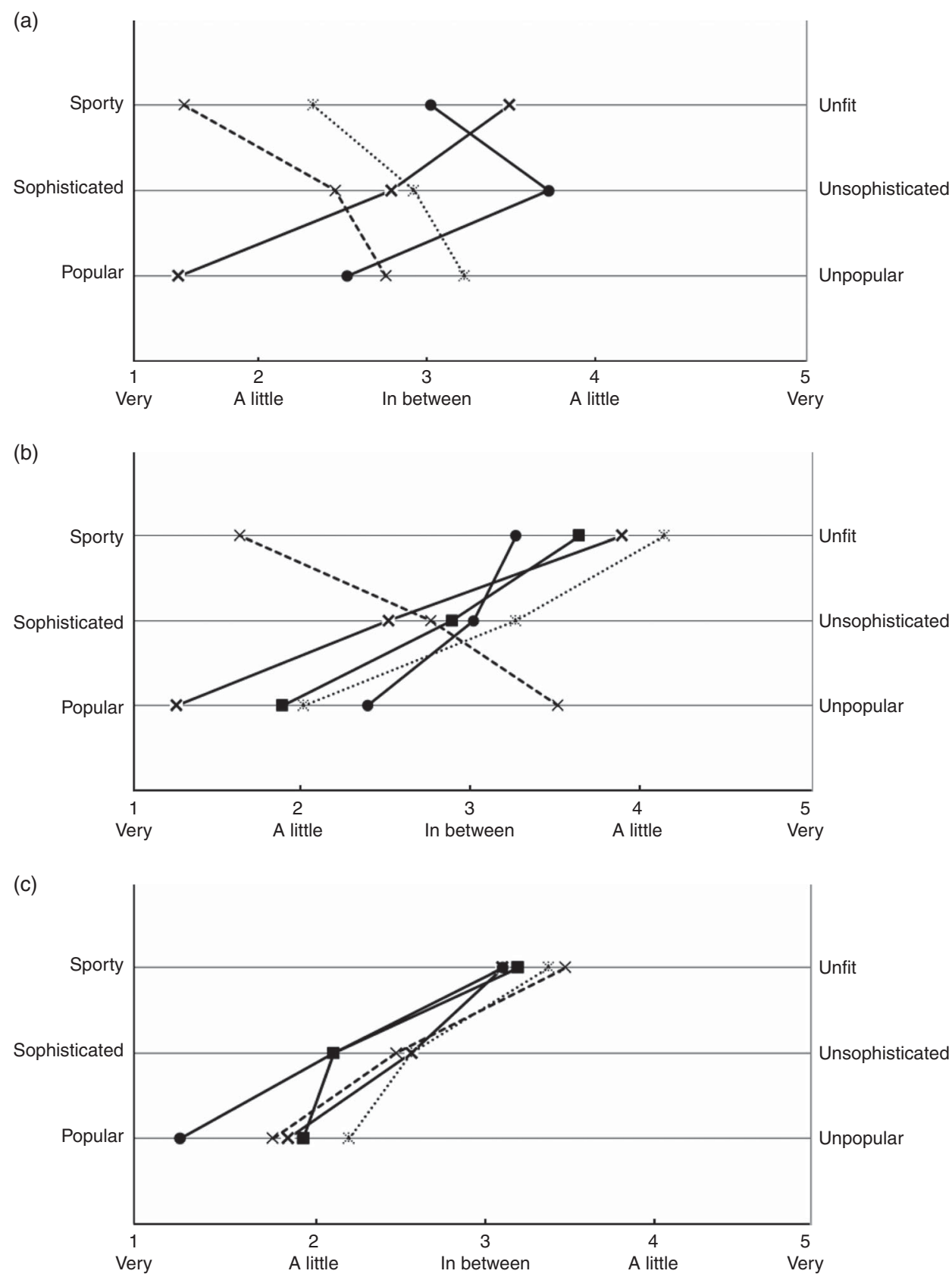

Fig. 1 Mean ratings on semantic differential scales (with 1 indicating strong positive perceptions and 5 indicating strong negative perceptions) for (a) users of beverage brands $(\rightarrow \leftarrow$, mean Coca-Cola; - ----, mean Mount Franklin; ..-*-.., mean Goulburn Valley;

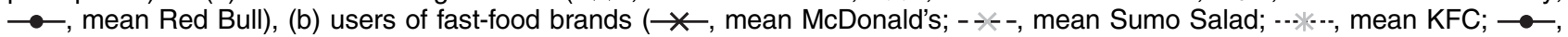
mean Red Rooster; $\rightarrow-$, mean Dominos) and (c) users of snack brands ( $\underset{-}{-}$, mean Mars; ---- , mean Freddo Frog; ---*--, mean Pringles; $\multimap-$, mean Cadbury; —-, mean Red Rock Deli) in an online survey by children aged 10-16 years (n 417), New South Wales, Australia, October-November 2014

they would try to make friends with them and that the person would have a similar personality to them. More children perceived that their parents would like the personified brand when this was a 'healthier' product (Mount Franklin water, Goulburn Valley juice, Sumo Salad) and also thought that these personified brands would be smart and good at sport. However, the three 'healthier' brands were perceived to be in the bottom five brands in terms of both popularity and whether other children would make friends with them.

The number of brands that children reported that they would make friends with (summation of the seven brands viewed for the statement 'I would try to make friends with them', with a score of 1 point for each brand with 'agree' and 'strongly agree') was compared with their previous engagement with ('liking' of) food brands on the social 
media site Facebook (Table 3). Those children who had liked food and beverage brands on Facebook agreed that they would try to make friends with significantly more of the food/drink brands if they were a new person at their school compared with those who had not liked brands on Facebook (mean $3.71 v .3 \cdot 21, t_{2}=-2 \cdot 10, P=0.04$ ). There was no significant difference between children who had engaged with food brands on Facebook and those who had not when considering agreement that other children would try to make friends with the personified brands (mean $4.29 v .3 .87, t_{2}=-1.73, P=0.08$ ). Summing the statement 'This person would have a similar personality to me' to indicate brand connection to self, there was no difference in this parameter by age group or volume of commercial television watched.

\section{Discussion}

The present study sought to explore children's brand associations and attachments for frequently promoted food and beverages in Australia, as an indicator of brand equity and likely intention to purchase and consume these brands. Children demonstrated strong positive affect to certain brands, perceiving some unhealthy food brands to have positive attributes, desirable user traits and alignment to their own personality. The eleven unhealthy brands were generally perceived more positively than the three 'healthier' brands. Unhealthy brands were rated as more cool, fun and exciting than 'healthier' brands; users of unhealthy brands were viewed as more popular; and it was perceived that other children would be more likely to make friends with the personified unhealthier brands. Alternatively, users of 'healthier' brands were seen to be more sophisticated and sporty, and personified 'healthier' brands would be liked more by parents, be smart and be good at sport. Younger children aged 10-12 years reported more favourable attitudes towards these food brands and users of the brands; however, there was no difference by age in agreement about statements of brands as human personalities.

The volume of commercial television viewed by children was not associated with food brand affect. While television viewing was used here as a proxy for exposure to unhealthy food promotions, children are known to be exposed to this marketing on most other media and settings where they gather ${ }^{(21)}$. Children who engaged with food brands on social media, identified here as 'liking' food and beverage brands on Facebook, were significantly more likely to report that they would make friends with brands if they were a person at their school. This identifies that children want to, and do, make 'friends' with these brands and form brand-self attachments. Although the concept of treating brands as a person is abstract, the internal consistency of children's responses, demonstrated by similar rankings of particular brands across attitude and attachment questions, suggests that children interpreted 
Table 3 Association between engagement with food brands on Facebook and agreement about making 'friends' with brands in an online survey among children aged 10-16 years ( $n$ 417), New South Wales, Australia, October-November 2014

\begin{tabular}{lcccc}
\hline & $\begin{array}{c}\text { I would try to make friends with this (branded) } \\
\text { person (sum of seven brands viewed) }\end{array}$ & $\begin{array}{c}\text { Other children would try to make friends with this } \\
\text { (branded) person (sum of seven brands viewed) }\end{array}$ \\
\cline { 2 - 3 } & Mean & SD & 1.56 & Mean \\
\hline Liked food brands on Facebook & $3.71^{*}$ & 1.85 & 4.29 & 1.59 \\
Had not liked food brands on Facebook & $3.21^{*}$ & 3.87 & 1.85 \\
\hline
\end{tabular}

For each brand, a score of 1 point was given for the responses 'strongly agree' and 'agree' to each statement. Mean values were significantly different: ${ }^{\star} P<0.05$.

the questions as intended and the questions were appropriate for this age group.

Children's ratings of brand personalities indicate the potential normative social influences of promotions. The majority of children perceived that Coca-Cola as a person would be popular and that other children would make friends with them. However, only half of children reported that they themselves would make friends with Coca-Cola. It is logical to perceive that a brand is popular and liked by others when it is frequently present and promoted. Cola-Cola marketing campaigns have also focused on friendship, such as the 'Share a Coke' campaign that encouraged consumers to buy a Coke bottle labelled with their own name and to share this with friends. These normative influences may lead to a change in individuals' behaviour in line with perceived social norms. Social norms are known to influence consumption behaviours, as seen with alcohol consumption in adolescents ${ }^{(22)}$ and tobacco smoking ${ }^{(23)}$, and the Theory of Reasoned Action identifies normative beliefs as a major determinant of behavioural intent ${ }^{(24)}$. Marketing may contribute to such normative beliefs through mere exposure, as well as the brand messages portrayed in promotions. In another Australian survey with children of primary school age ( $n$ 858) higher volume of television viewing was associated with more positive attitudes towards unhealthy foods, stronger perceptions that other children ate unhealthy food more often and a higher reported frequency of consumption of unhealthy food (all $P<0 \cdot 001)^{(19)}$.

The Cadbury brand was viewed as popular and, if the brand was a person, would be someone that other children would like. In this case, children perceived that their parents would also like Cadbury as a person and that they themselves would try to make friends with them. As such, Cadbury is perceived by children to be a more acceptable brand with which to be associated. This difference in perceptions of brands as appropriate for children is likely to be at least partially influenced by the target of brands' advertising. Cadbury tends to target young children, using cartoons and family images, and Cadbury's own market research identifies the brand as having 'core values of goodness and quality ${ }^{(25)}$. Alternatively, Coca-Cola targets adolescents and young adults through the use of tie-ins with music, sport and celebrities.
The brand personality traits of 'smart' and 'sporty' were viewed by children as indicators of healthiness, with Mount Franklin water, Sumo Salad and Goulburn Valley juice all rating higher than other brands for these domains when asked about the brand as a person. Children also believed their parents would approve of these brands. However, these brands were generally ranked lower for popularity, emphasising the normative beliefs that 'healthier' foods are less desirable despite children perceiving that these may be more appropriate based on health and parental perceptions. This was also highlighted by the consistent inverse association found between popularity of users of brands and sportiness, identified across all product categories. However, interestingly, younger children rated users of KFC as more sporty than older children and this link to sport may be a result of the highly visible KFC sponsorship of elite cricket in Australia ${ }^{(26)}$. With the exception of Red Bull, the five lowest rated brands on the scales of 'cool', 'fun' and 'exciting' were all 'healthier' choices, including water, juice, a salad bar and Red Rooster, which promotes itself as selling family meals. Red Bull energy drink was an anomaly. Children recognised that parents would not approve of this brand-as-a-person, but they also rated it unfavourably in terms of perceived brand attributes and users of brands, with users seen to be 'unsophisticated'. This is promising, given that consumption of energy drinks is not recommended at any age, but particularly for young people, given risks of caffeine toxicity $^{(27)}$. However, intakes of these drinks tends to increase at ages slightly older than the study sample ${ }^{(28)}$.

Brands that are ostensibly seen to appeal to adults, including Red Rock Deli crisps, were also rated favourably by children, with the brand seen to be cool and exciting. This has implications for food marketing policy recommendations, whereby any restrictions on marketing to children should take a broad definition and not only relate to food products or advertising that are designed to appeal to children. In a framework for legislation for food marketing to children that was developed by the Obesity Policy Coalition in Victoria, Australia, unhealthy food advertisements 'directed to children' (and therefore to be restricted) were defined as including advertisements intended or likely to appeal to children, and any unhealthy food advertisement that is likely to be seen or heard by children ${ }^{(29)}$. 
Also of policy relevance is children's positive affect towards corporate branding, as distinct from product branding. Corporate brands, such as McDonald's, also have identities that are familiar to and are positively viewed by children. Where these corporations predominantly produce and sell unhealthy food and beverage choices, consideration should be given to limiting children's exposures to corporate branding. In most existing food marketing regulations internationally, restrictions are based on the nutritional profile of food products $^{(30)}$, to the exclusion of any restrictions on corporate branding.

Other studies assessing children's preferences for food brands have typically been experimental in nature and have tested reported food choice following exposure to food brand $v$. other advertisements ${ }^{(31,32)}$ or branded $v$. plain packaging ${ }^{(33)}$. The latter study, which assessed children's ( $n$ 63) preferences for identical foods served in plain or McDonald's packaging, highlights the power of brands and brand equity. Children aged 3-5 years rated foods in McDonald's packaging significantly more favourably, even for foods not typically sold at McDonald's ${ }^{(33)}$. Brand name familiarity has also been shown in other studies to influence children's food choices for both healthy and unhealthy foods ${ }^{(34)}$, indicating that brand familiarity can lead to perceptions of product quality and worth.

The current study is limited by its cross-sectional design and mode of survey delivery. Data were collected for children living in one state of Australia (the most populous state) only and the extent that the findings apply more broadly to children from other areas of Australia is unknown. However, food consumption patterns for discretionary and core foods are similar across Australian States and Territories ${ }^{(35)}$ and rates of television food advertising are also similar ${ }^{(36)}$. The use of the consumer research panel for recruiting the sample may have introduced some response bias, given such panels are typically skewed towards older females. However, quota sampling ensured that a spread of socio-economic backgrounds was achieved and an approximately equal distribution of children by age and sex. While the survey tool was tested for face validity prior to use, no further psychometric testing of the tool was undertaken to assess, for example, repeatability or construct validity. Further, a sample of 400 children was selected to allow comparisons between demographic groups; however, power calculations were not undertaken. Post hoc power calculations revealed that a sample of 1396 children would have been needed to detect a significant difference in the mean perception of unhealthy food brands (mean of cool, fun and exciting scales) between higher and lower television viewers, based on median split $(1.17 v .1 .23$, noting that a higher score indicates more unfavourable ratings). The study sample was underpowered to detect this difference. However, the relevance of the difference between groups is questionable as both high and low television viewers rated unhealthy brands to be 'very' favourable. Future studies could employ qualitative methodologies to more fully explore meanings of brands for children. Longitudinal or experimental studies could elucidate causal relationships between brand exposures and affect, and between this affect and consumption intentions and behaviours. Investigations with younger children would also be useful. Akin to tobacco brand recognition among 3-6-year-olds ${ }^{(37)}$, studies on 'junk' food brand awareness and associations in pre-school children would provide evidence of the potential power of food marketing on young and vulnerable minds.

\section{Conclusion}

Exposures to unhealthy food brands inevitably lead to children's familiarity with these brands and the development of strong affects towards, and beliefs about, these brands, generating brand equity. Australian children have frequent and repeated exposures to persuasive and engaging food marketing spanning media platforms and settings where they congregate, the majority of which promote unhealthy food choices. The ubiquity of unhealthy food promotions exerts normative social influence on children, whereby frequently promoted brands (both corporate brands and product brands) are seen to be popular with others. While the findings show that children are aware of brand 'healthiness' as an attribute, this competes with other more positive attributes in terms of image and association, emphasising the challenge of health and nutrition messaging to counter this marketing. The 'persuasive power' of promotions is important in developing brand affect, including the formation of brand relationships through branded messages and brand-user engagement on new media. Restricting both the extent of children's exposure to unhealthy food marketing and the persuasive nature of product and brand marketing across all media platforms is an important part of efforts to improve children's nutrition and diet-related health.

\section{Acknowledgements}

Financial support: This study was funded by the Australian National Preventive Health Agency and the Australian Research Council (grant number LP0989387). The funder had no role in the design, analysis or writing of this article. Conflict of interest: None. Author's contributions: B.K., B.F., L.K. and K.C. conceptualised the study. B.K. and B.F. drafted the survey questions and led the data collection. All authors contributed to the final questionnaire and the survey process. B.K. undertook the analyses and drafted the manuscript. All authors read and approved the final manuscript. Ethics of human subject participation: The study was approved by the University of Sydney Human Research Ethics Committee. 


\section{Supplementary material}

To view supplementary material for this article, please visit http://dx.doi.org/10.1017/S1368980016001452

\section{References}

1. Roberto CA, Swinburn B, Hawkes C et al. (2015) Patchy progress on obesity prevention: emerging examples, entrenched barriers, and new thinking. Lancet 385, 2400-2409.

2. World Health Organization (2010) Set of Recommendations on the Marketing of Foods and Non-Alcoholic Beverages to Children. Geneva: WHO.

3. Kelly B, King L, Baur L et al. (2013) Monitoring food and non-alcoholic beverage promotions to children. Obes Rev 14, 59-69.

4. Galbraith-Emami S \& Lobstein T (2013) The impact of initiatives to limit the advertising of food and beverage products to children: a systematic review. Obes Rev 14, 960-974.

5. Hawkes C \& Lobstein T (2011) Regulating the commercial promotion of food to children: a survey of actions worldwide. Int J Pediatr Obes 6, 83-94.

6. World Cancer Research Fund International (2015) NOURISHING framework - Restrict food marketing. http://www. wcrf.org/int/policy/nourishing-framework/restrict-foodmarketing (accessed August 2015).

7. Barry TE \& Howard DJ (1990) A review \& critique of the hierarchy of effects in advertising. Int J Advert 9, 121-135.

8. Kelly B, King L, Chapman K et al. (2015) A hierarchy of unhealthy food promotion effects: identifying methodological approaches and knowledge gaps. Am J Public Health 105, e86-e95.

9. Aaker DA (1991) Managing Brand Equity: Capitalising on the Value of a Brand Name. New York: The Free Press.

10. Buil I, de Chernatony L \& Martínez E (2013) Examining the role of advertising and sales promotions in brand equity creation. J Bus Res 66, 115-122.

11. Park W, MacInnis JDP, Eisingerich A et al. (2010) Brand attachment and brand attitude strength: conceptual and empirical differentiation of two critical brand equity drivers. J Market 74, 1-17.

12. Dias M \& Agante L (2011) Can advergames boost children's healthier eating habits? A comparison between healthy and non-healthy food. J Consum Behav 10, 152-160.

13. Caprara GV, Barbaranelli C \& Guido G (2001) Brand personality: how to make the metaphor fit? J Econ Psychol 22, 377-395.

14. Piaget J (editor) (1929) The Child's Conception of the World. London: Trench, Trubner \& Co Ltd.

15. Livingstone S \& Helsper E (2004) Advertising foods to children: understanding promotion in the context of children's daily lives. http://core.ac.uk/download/pdf/94835. pdf (accessed April 2015).

16. Keller KL (1993) Conceptualizing, measuring, and managing customer-based brand equity. J Market 57, 1-22.

17. Australian Bureau of Statistics (2011) Census of Population and Housing: Socio-Economic Indexes for Areas (SEIFA). http://www.abs.gov.au/ausstats/abs@.nsf/mf/2033.0.55.001 (accessed March 2015).

18. Chebat JC \& Daoud F (2003) Effects of F1 Grand Prix sponsorship by cigarette brands on adolescents' cognitive and behavioural responses. Int J Sports Market Sponsorsh 5, 93-104.
19. Dixon HG, Scully ML, Wakefield MA et al. (2007) The effects of television advertisements for junk food versus nutritious food on children's food attitudes and preferences. Soc Sci Med 65, 1311-1323.

20. Kelly B, Baur LA, Bauman AE et al. (2011) Food company sponsors are kind, generous and cool: (mis)conceptions of junior sports players. Int J Behav Nutr Phys Act 8, 95.

21. Cairns G, Angus K, Hastings G et al. (2013) Systematic reviews of the evidence on the nature, extent and effects of food marketing to children. A retrospective summary. Appetite 62, 209-215.

22. Rimal RN \& Real K (2005) How behaviors are influenced by perceived norms. A test of the theory of normative social behavior. Commun Res 32, 389-414.

23. Chapman S \& Freeman B (2008) Markers of the denormalisation of smoking and the tobacco industry. Tob Control 17, 25-31.

24. Fishbein M \& Ajzen I (editors) (2010) Predicting and Changing Behavior. The Reasoned Action Approach. New York: Psychology Press.

25. The Irish Times Business 2000 Fifth Edition (2015) Brand development by identifying brand values. http://www. business2000.ie/pdf/pdf_5/cadbury_5th_ed.pdf (accessed August 2015).

26. Colagiuri S \& Caterson ID (2008) KFC sponsorship of cricket. Med J Aust 189, 415-416.

27. Gunja N \& Brown JA (2012) Energy drinks: health risks and toxicity. Med J Aust 196, 46-49.

28. Abbott RA, Macdonald D, Stubbs CO et al. (2008) Healthy Kids Queensland Survey 2006 - Full Report. https://www. health.qld.gov.au/ph/documents/hpu/healthykidsqld2006. pdf (accessed July 2015).

29. MacKay S, Antonopoulos N, Martin J et al. (2011) A comprehensive approach to protecting children from unhealthy food advertising. http://www.opc.org.au/down loads/positionpapers/protecting-children-unhealthy-foodadvertising-promotion.pdf (accessed November 2015).

30. Yale Rudd Center for Food Policy \& Obesity (2013) Pledges on food marketing to children worldwide. http://www. yaleruddcenter.org/marketingpledges/ (accessed June 2013).

31. Boyland EJ, Harrold JA, Kirkham TC et al. (2011) Food commercials increase preference for energy-dense foods, particularly in children who watch more television. Pediatrics 128, e93-e100.

32. Redondo I (2012) The effectiveness of casual advergames on adolescents' brand attitudes. Eur J Market 46, 1671-1688.

33. Robinson TN, Borzekowski DG, Matheson DM et al. (2007) Effects of fast food branding on young children's taste preferences. Arch Pediatr Adolesc Med 161, 792-797.

34. Levin AM \& Levin IP (2010) Packaging of healthy and unhealthy food products for children and parents: the relative influence of licensed characters and brand names. J Consum Behav 9, 393-402.

35. Australian Bureau of Statistics (2015) Australian Health Survey: Nutrition - State and Territory results, 2011-12. http://www.abs.gov.au/ausstats/abs@.nsf/Lookup/by\% 20Subject/4364.0.55.009 2011-12 Main\%20Features Key\% 20Findings 1 (accessed Februrary 2016).

36. Roberts M, Pettigrew S, Chapman K et al. (2013) The advertised diet: an examination of the extent and nature of food advertising on Australian television. Health Promot $J$ Aust 24, 137-142.

37. Fischer PM, Schwartz MP, Richards JW et al. (1991) Brand logo recognition by children aged 3 to 6 years. Mickey Mouse and Old Joe the Camel. JAMA 266, 3145-3148. 